
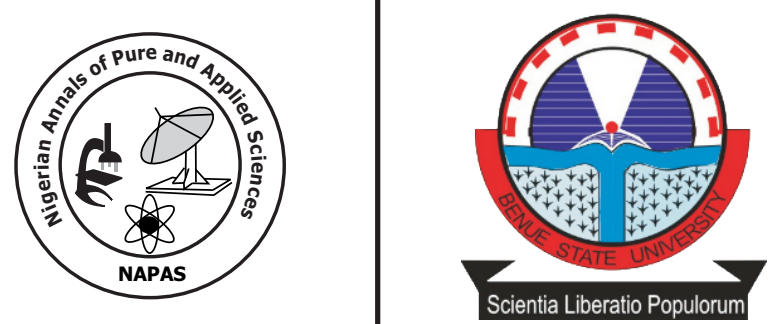

\title{
Principal Component Analysis of Morphometric Traits of West African Dwarf Goats
}

\author{
*Dudusola, I.0 ${ }^{1}$., Oseni, S. $0^{1}$., Popoola, M. A $^{2}$. and Jenyo, A $^{1}$. \\ ${ }^{1}$ Department of Animal Sciences, \\ Obafemi Awolowo University, Nigeria \\ ${ }^{2}$ Federal College of Animal Health and Production Technology, \\ Ibadan, Nigeria
}

*Corresponding author *dipodudu2000@yahoo.com

\begin{abstract}
The study was conducted to evaluate the principal component analysis of phenotypic attributes of West African Dwarf (WAD) goat. Data collected on the live body weight and twelve morphometric traits of the goats which were categorised into four age groups based on their dentition. The age groups were: less than 2years old, 23years old, 3-4 years old and 4 years old. The data were subjected to a PCA and Cluster analyses using the multivariate procedure components of SAS (2003). Result revealed that highest values of morphometric traits were obtained in goats that of 4 years old. The rate of increase in body weight and other morphometric traits was high in age group of $<2$ years to age 2-3years compared to differences observed in others across the age group. Heart Girth had the highest correlation with body weight. Foreleg, neck, ear and hind leg lengths; wither height and rump height were weakly correlated with the body weight of the goats. Result revealed that two Principal components were retained in the first age group (age group $<2$ years) which accounted for $72.99 \%$ of the total variation. The first PC alone accounted for $63.13 \%$ of the total variation while PC2 accounted for the remaining $9.86 \%$. From this study, it was concluded that there is interdependence among body weight and morphometric traits and that morphometric traits can be used in predicting live weight of WAD goats; PCA and Cluster could be exploited in breeding and selection programmes to acquire highly coordinated animal bodies using fewer measurements.
\end{abstract}

Key words: Body, morphometric, goat, principal, traits 


\section{Introduction}

Goats play a significant role in the economy and nutrition of landless, small and marginal farmers in most developing countries (Khan et al., 2006). In ranking, they are next to cattle in income generation and their meat is quite popular, well accepted and relished (Ladele et al., 1996). Population of goats in Nigeria is estimated at 53.8 million (FAOSTAT, 2011) in which traditionally reared stock contributes $99.97 \%$, and the remaining $0.03 \%$ of the stock is commercially managed. The three most important goat breeds traditionally recognized in Nigeria are the Red Sokoto (RS), the West African Dwarf (WAD) goats and the Sudan Sahel (Ebozoje and Ikeobi, 1998). The RS goats are well known for their usefulness in the tanning industries while the WAD goats are known for their tolerance to trypanosomiasis. Morphometric measurements have been used to evaluate the characteristics of various breeds of animals by several researchers, and could provide first-hand information on the suitability of animals for selection (Ogah, 2011; Oseni and Ajayi, 2010). Analysis of variance and correlations are widely used to characterize phenotypic and genetic relationships among body measurements of animals (Dietl, et al., 2005).

Yakubu et al., (2011) reported that principal component analysis (PCA) is a valuable refinement. According to Everitt et al., (2001), principal component analysis is a multivariate method which transforms the variables in a multivariate data set into new variables, which are uncorrelated with each other and accounted for decreasing proportions of the total variance of the original variables. PCA can be an intermediary analysis for other analysis like cluster analysis, Several researchers have employed principal component analysis to extract factors contributing towards variation amongst individual animals based on body measurements (Oseni and Ajayi, 2012). According to Salako and Ngere (2002), there is need to study variations among local goat populations through breed characters to facilitate their efficient utilization using a multivariate approach. Thus this study sought to describe the morphometric characteristics of WAD goat in the South Western part of Nigeria using principal component and cluster analyses.

\section{Materials and methods}

The study was conducted in of Osun state, South-western Nigeria. Data were collected on the live body weight and twelve morphometric traits of WAD goats across the 3 districts in the state using stratified and random sampling technique.
The three districts were Osun West, Osun Central and Osun East. Two local government areas were randomly selected in each district. From each local government area, three locations were randomly selected and twenty goats were sampled from each location to give a total of 360 goats sampled.

The sampled goats were categorised into four groups based on their dentition using the FAO (1999) breed descriptor. The age groups were; less than 2 years old, 2-3years old, 3-4 years old and older 4 years. Data were collected on the live body weight and twelve morphometric traits which are body weight, body length, rump height, wither height, foreleg length, hind leg length, neck circumference, heart girth, ear length, face length, shoulder width, rump width and neck length. Body weights of the animals were taken using a digital hanging scale and other morphometric traits were taken using a measuring tape.

The data were subjected to a PCA and Cluster analyses using the multivariate procedure components of SAS (2003) using PROC.PRINCOMP and PROC.CLUSTER. The data obtained were analyzed to obtain mean, standard errors and standard deviation and coefficient of variation for body weight and the twelve body measurements using PROC.MEANS procedure of SAS. Partial correlation was used to obtain the relationship among the variables in data set using PROC.CORR procedure. From the correlation matrix, data were generated for the principal component factor analysis using PROC.PRICOMP procedure of SAS. KaiserMeyer-Olkin measures of sampling adequacy and Bartlett's Test of Sphericity were computed to test the validity of the factor analysis of the data sets.

\section{Results}

The summary of the descriptive statistics of morphometric traits of WAD goats is presented in Table 1. Result revealed that heart Girth recorded the highest mean $(57.95 \pm 0.32 \mathrm{~cm})$ while ear Length recorded the lowest mean $(10.20 \pm 0.04 \mathrm{~cm})$. Also relative low variability (coefficient of variation) was obtained; the highest $\mathrm{CV}$ was obtained in body weight and the lowest was obtained in fore-leg length.

West African dwarf goats that were older than 4 years had the highest mean for all the morphometric traits (Table 2). This shows that the weight and morphometric traits increases with increase in age and age significantly influenced the morphometric traits. Heart girth has the highest mean, followed by the body length, rump height, wither height in all the age groups. Rump width, ear length, foreleg length, hind-leg length 
has the lowest mean across all the age groups.

The phenotypic correlation of morphometric traits of WAD goats is presented in Table 3. Result shows significant correlation coefficients between the traits. Heart Girth had the highest correlation with body weight, other traits of high correlations with body weight were body length, shoulder width, rump width, neck circumference and face length. Fore-leg, neck, ear and hind-leg lengths; wither height and rump height were weakly correlated with the body weight of the goats. Correlation between wither height and rump height was strongest $(r=0.880)$ while the relationship between fore-leg length and shoulder width was the weakest $(r=0.16)$.

Result revealed that two Principal components were retained in the first age group (less than 2years) which accounted for $72.99 \%$ of the total variation (Table 4). The first PC alone accounted for $63.13 \%$ of the total variation while PC2 accounted for the remaining 9.86\%.In age 23 years, four Principal Components were retained and they accounted for $73.55 \%$ of the total variance. The first Principal Component accounted for $40.73 \%$ of the total variance while the second PC accounted for $12.33 \%$, the third Principal component accounted for $10.93 \%$ while the fourth Principal Component accounted for $9.57 \%$ of the remaining variance. In age group of 3-4years, three Principal Components were retained and they accounted for $64.88 \%$ of the total variations. Principal Component one explained $37.57 \%$ of the total variance, the second variance explained $15.14 \%$, the third principal components explained $12.17 \%$ of the remaining variance. Four PCs were retained with a cumulative of $74.20 \%$ in goats that were older than 4 years. The first PC accounted for $45.59 \%$ of the total variance, the second Principal Component accounted for $13.95 \%$. The third accounted for $9.25 \%$ while the fourth Principal Component accounted for $8.41 \%$ of the total variation.

Four PCs were retained in all the age groups except in goats that were less than 2 years old and those that were 3-4 years old where two PCs and three PCs were retained respectively. HG, BW, $\mathrm{BL}, \mathrm{RW}, \mathrm{SW}$ and RW have high loadings for PC1 in all the age groups. HLL and FLL has high loading for PC2 in all the age group except age group 3-4years, where HLL has high loading for $\mathrm{PC} 1$ and the loading weight is higher in PC 3 than PC 2 in age group 2-3 years. NL has high loading for PC 3 in age group 3- 4years and highest loading for PC 4 in goats that were older than 4 years (Table 5)

Figure 1 showed the component plot for the two principal components retained in the overall age group. Most of the components has high positive loading for $\mathrm{PC} 1$ and clustered around PC1. Hind and Fore leg length has high loading for $\mathrm{PC} 2$ and they clustered away from the rest towards positive part of PC2.

Table 1: Descriptive Statistics of the Live Body Weight and Morphometric Traits for Oveall age groups

\begin{tabular}{llllllll}
\hline & Range & Min & Max & Mean & Std Err & SD & CV \\
\hline BW & 32 & 7 & 39 & 16.23 & 0.25 & 4.74 & 29.21 \\
BL & 32.10 & 34.20 & 66.30 & 49.91 & 0.29 & 5.58 & 11.18 \\
RH & 20.60 & 33.20 & 53.80 & 45.29 & 0.18 & 3.42 & 7.55 \\
WH & 19.50 & 32.00 & 51.50 & 42.56 & 0.17 & 3.20 & 7.52 \\
FLL & 4.90 & 8.10 & 13.00 & 10.54 & 0.04 & 0.74 & 7.02 \\
HLL & 5.60 & 9.90 & 15.50 & 12.31 & 0.05 & 0.89 & 7.23 \\
NC & 20.10 & 16.50 & 36.60 & 24.53 & 0.14 & 2.54 & 10.36 \\
HG & 32.90 & 42.00 & 74.90 & 57.95 & 0.32 & 6.09 & 10.51 \\
EL & 4.70 & 7.90 & 12.60 & 10.20 & 0.04 & 0.83 & 8.14 \\
FL & 7.30 & 11.60 & 18.90 & 15.88 & 0.07 & 1.26 & 7.94 \\
SW & 9.90 & 6.30 & 16.20 & 11.73 & 0.08 & 1.53 & 13.04 \\
RW & 7.80 & 6.20 & 14.00 & 10.41 & 0.08 & 1.49 & 14.31 \\
NL & 12.60 & 9.80 & 22.40 & 16.20 & 0.08 & 1.58 & 9.75
\end{tabular}

$\mathrm{BW}=$ Body Weight, $\mathrm{BL}=$ Body Length, $\mathrm{RH}=$ Rump Height, $\mathrm{WH}=$ Wither Height, FLL=Fore-leg Length, HLL=Hind leg Length, $\mathrm{NC}=$ Neck Circumference, $\mathrm{HG}=$ Heart Girth, EL=Ear Leng th, $\mathrm{FL}=$ Face Length, $\mathrm{SW}=$ Shoulder Width, RW=Rump Width, $\mathrm{NL}=$ Neck Length.

SE- Standard Error; SD- Standard Deviation CV- Coefficient of Variation 
Table 2: Effects of age on body weight and morphometric traits of WAD goats

\begin{tabular}{lllll}
\hline TRAITS (cm) & ?2yrs & 2-3yrs & 3-4yrs & ?4yrs \\
\hline BW (kg) & $11.31 \pm 0.31$ & $15.64 \pm 0.30$ & $17.78 \pm 0.35$ & $20.18 \pm 0.47$ \\
BL & $43.62 \pm 0.36$ & $49.87 \pm 0.51$ & $52.53 \pm 0.39$ & $53.61 \pm 0.42$ \\
RH & $42.33 \pm 0.31$ & $45.35 \pm 0.41$ & $46.14 \pm 0.26$ & $47.31 \pm 0.20$ \\
WH & $39.57 \pm 0.23$ & $42.45 \pm 0.39$ & $43.41 \pm 0.23$ & $44.44 \pm 0.20$ \\
FLL & $10.34 \pm 0.83$ & $10.79 \pm 0.08$ & $10.99 \pm 0.06$ & $10.40 \pm 0.08$ \\
HLL & $12.05 \pm 0.93$ & $12.63 \pm 0.09$ & $12.48 \pm 0.08$ & $12.07 \pm 0.09$ \\
NC & $22.59 \pm 0.19$ & $24.23 \pm 0.23$ & $25.06 \pm 0.22$ & $26.23 \pm 0.27$ \\
HG & $51.22 \pm 0.41$ & $57.23 \pm 0.48$ & $59.94 \pm 0.41$ & $63.38 \pm 0.45$ \\
EL & $9.60 \pm 0.06$ & $10.31 \pm 0.10$ & $10.38 \pm 0.09$ & $10.51 \pm 0.07$ \\
FL & $14.73 \pm 0.08$ & 15.660 .14 & $16.33 \pm 0.09$ & $16.79 \pm 0.09$ \\
SW & $10.39 \pm 0.11$ & $11.58 \pm 0.15$ & $12.13 \pm 0.13$ & $12.80 \pm 0.13$ \\
RW & $8.55 \pm 0.09$ & $10.43 \pm 0.13$ & $11.07 \pm 0.08$ & $11.59 \pm 0.08$ \\
NL & $14.83 \pm 0.13$ & $16.32 \pm 0.19$ & $16.44 \pm 0.11$ & $17.21 \pm 0.12$
\end{tabular}

$\overline{\mathrm{BW}}=$ Body Weight, $\mathrm{BL}=$ =Body Length, $\mathrm{RH}=$ Rump Height, $\mathrm{WH}=$ Wither Height, $\mathrm{FLL}=$ Fore $\quad$-leg Length, HLL=Hind leg Length, $\mathrm{NC}=$ Neck Circumference, HG=Heart Girth, EL=Ear Length, FL=Face Length, SW=Shoulder Width, RW=Rump Width, NL=Neck Length.

$\mathrm{SE}-$ Standard Error.

Table 3: Partial Correlations among Variables in the Overall Age Groups

\begin{tabular}{|c|c|c|c|c|c|c|c|c|c|c|c|c|c|}
\hline & BW & BL & RH & WH & FLL & HLL & $\mathrm{NC}$ & HG & EL & FL & SW & RW & NL \\
\hline BW & 1.00 & .674 & .409 & .394 & .214 & .323 & .526 & .796 & .308 & .517 & .644 & .618 & .253 \\
\hline BL & & 1.00 & .530 & .527 & .313 & .358 & .475 & .668 & .453 & .606 & .627 & .641 & .335 \\
\hline RH & & & 1.00 & .880 & .461 & .360 & .341 & .503 & .447 & .585 & .410 & .530 & .484 \\
\hline WH & & & & 1.00 & .461 & .362 & .383 & .481 & .437 & .578 & .400 & .506 & .528 \\
\hline FLL & & & & & 1.00 & .659 & .203 & .254 & .315 & .347 & .160 & .325 & .280 \\
\hline HLL & & & & & & 1.00 & .296 & .359 & .281 & .367 & .243 & .334 & .200 \\
\hline $\mathrm{NC}$ & & & & & & & 1.00 & .510 & .274 & .484 & .472 & .480 & .227 \\
\hline HG & & & & & & & & 1.00 & .338 & .568 & 679 & .704 & .368 \\
\hline EL & & & & & & & & & 1.00 & .362 & .270 & .397 & .233 \\
\hline FL & & & & & & & & & & 1.00 & .547 & .580 & .462 \\
\hline SW & & & & & & & & & & & 1.00 & .611 & .315 \\
\hline RW & & & & & & & & & & & & 1.00 & .358 \\
\hline NL & & & & & & & & & & & & & 1.00 \\
\hline
\end{tabular}

$\mathrm{BW}=$ Body Weight, $\mathrm{BL}=$ =Body Length, $\mathrm{RH}=$ Rump Height, $\mathrm{WH}=$ Wither Height, $\mathrm{FLL}=$ Fore-leg Length, $\mathrm{HLL}=$ Hind leg Length,

$\mathrm{NC}=$ Neck Circumference, $\mathrm{HG}=$ Heart Girth, EL=Ear Length, FL=Face Length, SW=Shoulder Width, RW=Rump Width, NL=Neck Length.

Table 4: Total Variance Explained for All the Age Groups

\begin{tabular}{|c|c|c|c|c|c|c|c|c|c|c|c|c|}
\hline & $? 2 \mathrm{yr}$ & & & $2-3 \mathrm{yr}$ & & & $3-4 y r$ & & & ?4yrs & & \\
\hline Comp & Total & \%Var. & Cumm. & Total & $\%$ Var. & Cumm. & Total & $\%$ Var. & Cumm. & Total & \%Var. & Cumm. \\
\hline 1 & 7.58 & 63.13 & 63.13 & 4.89 & 40.73 & 40.73 & 4.51 & 37.57 & 37.57 & 5.11 & 42.59 & 42.59 \\
\hline 2 & 1.18 & 9.86 & 72.99 & 1.48 & 12.33 & 53.051 & 1.82 & 15.14 & 52.71 & 1.68 & 13.95 & 56.55 \\
\hline 3 & 0.75 & 6.28 & 79.27 & 1.31 & 10.93 & 63.98 & 1.46 & 12.17 & 64.88 & 1.11 & 9.25 & 65.80 \\
\hline 4 & 0.60 & 5.04 & 84.30 & 1.15 & 9.57 & 73.55 & 0.88 & 7.32 & 72.20 & 1.01 & 8.41 & 74.20 \\
\hline 5 & 0.43 & 3.58 & 87.88 & 0.80 & 6.68 & 80.23 & 0.81 & 6.78 & 78.98 & 0.80 & 6.70 & 80.90 \\
\hline 6 & 0.32 & 2.69 & 90.58 & 0.65 & 5.39 & 85.62 & 0.65 & 5.43 & 84.41 & 0.68 & 5.62 & 86.53 \\
\hline 7 & 0.27 & 2.29 & 92.86 & 0.52 & 4.33 & 89.95 & 0.56 & 4.70 & 89.11 & 0.53 & 4.43 & 90.56 \\
\hline 8 & 0.26 & 2.20 & 95.06 & 0.42 & 3.46 & 93.41 & 0.39 & 3.22 & 92.33 & 0.36 & 3.00 & 93.96 \\
\hline 9 & 0.20 & 1.64 & 96.71 & 0.33 & 2.77 & 96.18 & 0.36 & 3.03 & 95.36 & 0.26 & 2.15 & 96.11 \\
\hline 10 & 0.15 & 1.24 & 97.95 & 0.24 & 1.99 & 98.17 & 0.32 & 2.66 & 98.02 & 0.25 & 2.04 & 98.15 \\
\hline 11 & 0.15 & 1.22 & 99.16 & 0.16 & 1.36 & 99.53 & 0.18 & 1.46 & 99.47 & 0.14 & 1.19 & 99.34 \\
\hline 12 & 0.10 & 0.84 & 100.00 & 0.06 & 0.47 & 100.00 & .063 & 0.53 & 100.00 & 0.08 & 0.66 & 100.00 \\
\hline
\end{tabular}


Table 5: PCs Retained with their Eigenvectors for each of the Variables in all the Age Group

\begin{tabular}{|c|c|c|c|c|c|c|c|c|c|c|c|c|c|c|c|c|}
\hline & \multicolumn{2}{|c|}{ Overall } & \multicolumn{3}{|c|}{ ?2yrs } & \multicolumn{3}{|c|}{$2-3 y r s$} & \multicolumn{3}{|c|}{ 3-4yrs } & \multicolumn{5}{|c|}{ ?4yrs } \\
\hline & $\mathrm{PC} 1$ & PC2 & PC3 & $\mathrm{PC} 1$ & PC2 & $\mathrm{PC} 1$ & PC2 & PC3 & PC4 & PC1 & PC2 & PC3 & PC1 & PC2 & PC3 & PC4 \\
\hline BL & .893 & -.125 & .090 & .871 & -.267 & .731 & -.260 & .261 & -.297 & .812 & .165 & .023 & .725 & -.351 & -.080 & -.243 \\
\hline RH & .860 & .110 & -.310 & .889 & .049 & .814 & .069 & -.418 & -.092 & .680 & -.543 & .288 & .728 & .427 & .294 & .102 \\
\hline WH & .874 & .088 & -.302 & .886 & .133 & .752 & -.003 & -.531 & -.121 & .664 & -.491 & .403 & .758 & .425 & .172 & .154 \\
\hline FLL & .402 & .824 & .015 & .605 & .668 & .505 & .705 & .195 & .177 & .526 & -.628 & -.125 & .506 & .608 & -.396 & -.234 \\
\hline $\begin{array}{l}\text { HL } \\
\text { L }\end{array}$ & .399 & .770 & .336 & .581 & .658 & .348 & .616 & .529 & .196 & .678 & -.271 & -.326 & .600 & .401 & -.398 & -.359 \\
\hline NC & .687 & -.195 & .437 & .746 & -.050 & .214 & -.459 & .148 & .563 & .335 & .246 & -.535 & .605 & -.299 & -.241 & .205 \\
\hline HG & .892 & -.208 & .150 & .897 & -.181 & .802 & -.218 & .177 & -.071 & .677 & .449 & .013 & .785 & -.427 & .094 & -.064 \\
\hline EL & .671 & .134 & -.211 & .754 & .059 & .438 & .156 & .168 & -.612 & .543 & -.054 & -.415 & .344 & .153 & .731 & -.378 \\
\hline FL & .863 & -.093 & .059 & .812 & -.103 & .742 & .022 & -.126 & .389 & .701 & .212 & .030 & .776 & -.118 & -.211 & .267 \\
\hline SW & .817 & -.253 & .236 & .839 & -.244 & .557 & -.415 & .383 & .164 & .538 & .583 & .279 & .750 & -.497 & .034 & -.018 \\
\hline RW & .890 & -.161 & .044 & .795 & -.321 & .860 & -.154 & .154 & -.112 & .742 & .316 & -.072 & .681 & -.152 & .095 & -.104 \\
\hline NL & .731 & -.051 & -.364 & .783 & -.021 & .516 & .227 & -.449 & .283 & .113 & .190 & .742 & .372 & .281 & .127 & .679 \\
\hline
\end{tabular}

\section{Component Plot}

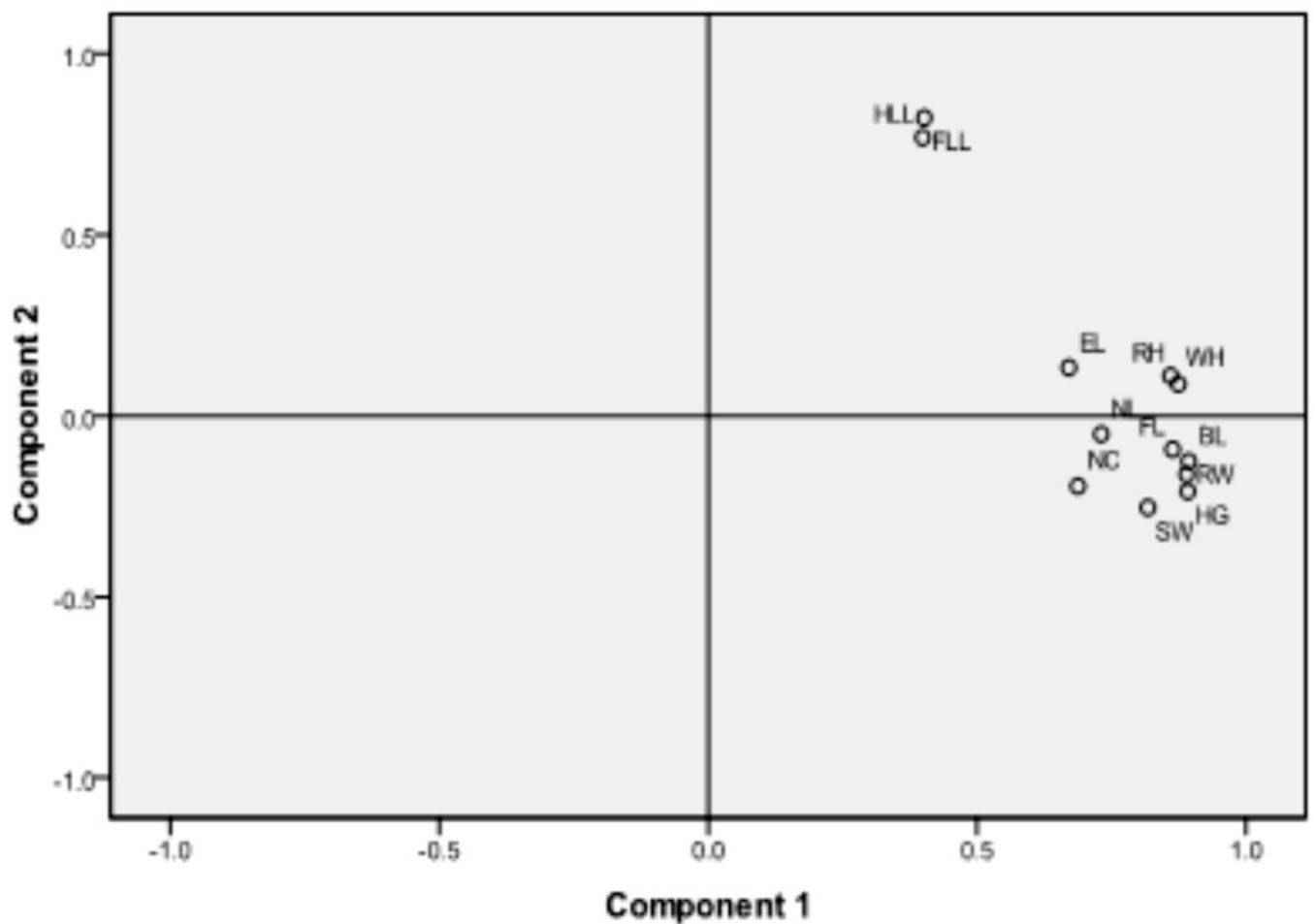

Fig. 1: Component Plot Showing Loadings of Components on PCs of WAD goat

\section{Discussion}

Age is an important factor which affects the morphometric traits of animals. Each measurement as observed in this study developed at different rate at different age groups indicating physiological growth which increases with age. Yakubu et al. $(2009 ; 2011)$ recorded similar cases in both white Fulani Cattle and Uda Sheep. According to Yakubu et al. (2009), the aggregation of morphometric traits into factors is age dependent. Some body parameters were early maturing and stopped growing before others. This is consistent with the findings of various earlier researchers, which is an indication that the essential body evolution of mammalian animals occurred before the maturity stage and growth follows a general pattern till maturity.

The rate of increase in $\mathrm{BW}$ and other morphometric traits was high in age 8 months $-<2$ years to age $2-<3$ years compared to differences observed in others across the age group. The foreleg length and hind-leg length reduced at the last age group. This is in accordance with Samuel and Salako (2008). The relative balance between the heights at rump and wither measurement suggested that the animal maintain good balance on standing and this is an important adaptive feature to the environment. Yunusa et al. (2013) 
and Agaviezor et al. (2012) reported similar for WAD sheep and Uda and Balami Sheep respectively.

The traits that were highly correlated with body weight in all the age groups included height girth, body length, rump width and shoulder width. This is an indication that, depending on genetic correlations, selection for these traits could result in responses in the correlated traits. Also, high positive relationship among traits suggests that they are under the same gene action and can also be predicted from one another singly or in combinations (Ogah et al., 2009).

Heart girth had the highest correlation with body weight in all the age groups. Mavule et al., (2012) reported similar case in all the age groups for Zulu sheep. Significant correlations of most of these traits have been reported by several workers (Salako, 2006; Mulyono et al., 2009). Salako (2006) reported correlation of up to 0.99 in the study of immature Uda sheep. These relatively large correlation coefficients reported by the author could have resulted from the stage of growth of animals used for that study. When studies are carried out on animals with actively dividing cells (actively growing), there are propensities for high correlation between body measurements, and also auto-correlation is mostly probable when small sample size is considered (Yunusa et al., 2013).

The HG, BW, BL, RW, SW has high loading for the first $\mathrm{PC}$ in all the age groups which is indicative of the general body size, It is also in agreement with most works on morphometric traits of every animals. The FLL and HLL have highest loadings on the second PC in all the age group except age group $3-<4$ years. This is indicative of the body shape of the animal. From table of PC extracted from all age group, the basic categories two PCs which are clearly stated. According to Yakubu et al. (2009), the aggregation of morphometric traits into factors is age dependent.

\section{Conclusion}

Based on the result of this study, it was concluded that there is interdependence among body weight and morphometric traits and that morphometric traits can be used in predicting live weight of WAD goats. It further concluded that WAD goats can be categorized into three and that PCA and Cluster could be exploited in breeding and selection programmes to acquire highly coordinated animal bodies using fewer measurements

\section{References}

Agaviezor, B.O., Peters, S.O., Adefenwa, M.A.,
Yakubu, A., Adebambo, O.A, Ozoje M., Ikeob,i C.O.N., Wheto, M., Ajayi,O.O., Amusan, S.A., Ekundayo, O.J., Sanni, T.M., Okpeku M., Onasanya, G.O., Donato, M.D, Ilori, B.M., Kizilkaya, K.

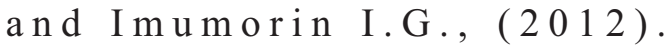
Morphological and DNA diversity of Nigerian indigenous sheep. Journal of Animal Science and Biotechnology, 3:38.

Dietl, G., Hoffmann S. and Reinsch, N., (2005). Impact of trainer and judges in the mare performance test of warm blood horses. Arch Tierz Dummerstorf, 48:113-120.

Ebozoje M.O. and Ikeobi, C.O.N. (1998). Colour variation and re-production in the West African Dwarf (WAD) goats. Small Ruminant Research, 27: 125-130

Everitt, B.S., Landau, S. and Leese, M., (2001). Cluster analysis. $4^{\text {th }}$ Edition, Arnold Publisher, London.

FAO, (1999). Food and Agriculture Organization of the United Nations. AGRI. Paper No. 25 , Rome, Italy.

FAOSTAT, (2011). Food and Agriculture Organization of the United Nations ( a va i l a ble a t http://faostat.fao.org/default.aspx). Accessed $19^{\text {th }}$ July, 2011.

Khan H, Muhammad F, Ahmad R, Nawaz G, Zubair R. and Zubair M. (2006). Relationship of body weight with linear body measurements in goats. Journal of Agricultural and Biological Science, 1 (3): 51-54.

Ladele A. A, Joseph K, Omotesho O. A. and Ijaiya T. O (1996). Sensory quality ratings, consumption pattern in Nigeria. British Journal of Food Science and Nutrition, 47:141-145.

Mavule, B.S.,Muchenjebv, Bezuidenhout C. C. and Kunene N.W (2012). Morphological structure of zulu sheep based on principal component analysis of body measurement small ruminant Research Nigeria. Animal genetic resources information, 1-9.

Mulyono RH, Gunawan A and Sumantri C (2009). Characteristics of Size and Shape of Body Dimension of Madura and Rote (Indonesia) Fat-Tailed Sheep Using Principal Component Analysis. The 1st International Seminar on Animal Industry 2009. Pp253- 258.

Ogah, D.M., (2011). Assessing size and conformation of the body of Nigerian indigenous Turkey. Slovakia Journal of Animal Science, 44, 21-27

Ogah, D.M. I.D Hassan and I.S Musa (2009). Path 
Coefficient Analysis of the Relationship between various Body measurement and Live weight in Immature West African Dwarf Goats, Institute of Animal Biology and Nutrition, 25:72-77.

Oseni, S. O. and Ajayi, B. A. (2010). Descriptive characterization of a Nigerian heterogenous rabbit population - Factors affecting litter traits. World Rabbit Science, 18:111-116.

Oseni, S. O. and Ajayi B. A., (2012). Morphological characterization and principal component analysis of body dimensions in Nigerian population of adult rabbits. Proc. $10^{\text {th }}$ World Rabbit Congress, Egypt, Sept., 3-6, 2012, pp 229233.

Salako, A. E. and Ngere, L. O. (2002). Application of Multifactorial Discriminant analysis in the Morphometric Structural Differentiation of West African Dwarf and Yankassa sheep in Southwest Nigeria. Nigeria Journal of Animal Production, 29(2): 163-167.

Salako, A. E. (2006). Principal component factor analysis of the morph structure of immature Uda sheep. International Journal of Morphology,24 (4): 571-574.

Samuel, O.K. and A.E. Salako, (2008). Body measurement characteristics of the West Dwarf (WAD) goat in deciduous forest zone of Southwestern Nigeria. African Journal of Biotechnology, 7(14): 25212526.

SAS (2003). Statistical Analysis System, User's Guide. Statistical Analysis Institute, Inc. Cary. North Carolina.

Yakubu A., Ogah D.M. and Idahor K.O. (2009). Principal component analysis of the morphostructural indices of White Fulani cattle. Trakia Journal of Science, 7: 67-73

Yakubu A., Salako A.E. and Abdullah A.R. (2011). Varimax Rotated Principal Component Factor Analysis of the Zoometrical Traits of Uda Sheep. Archivos de Zootecnia, 60 (231): 813-816.

Yunusa, A.J., Salako, A.E and Oladejo O.A. (2013). Principal component analysis of the morphostructure of Uda and Balami sheep of Nigeria. International Journal of Agricultural Sciences, 1(3):45 